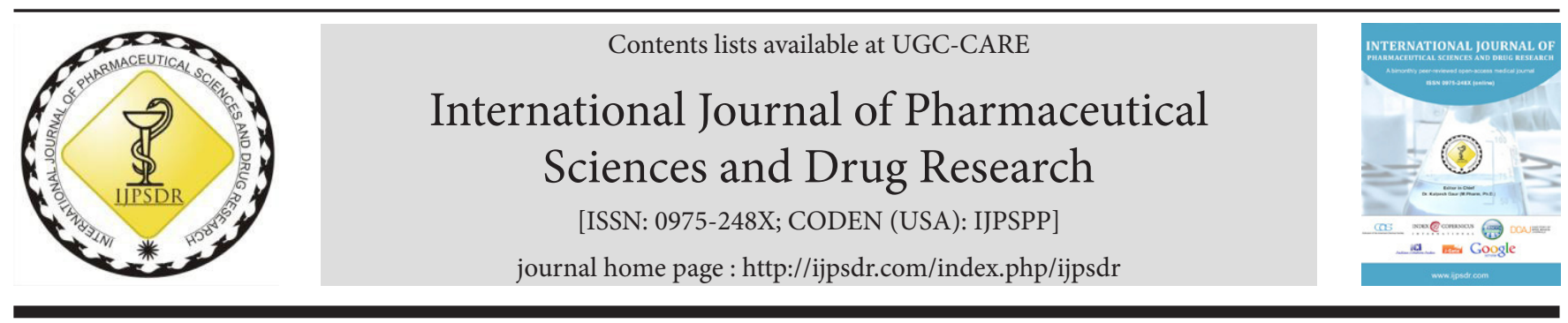

Research Article

\title{
Method Development and Validation of Gas Chromatography-Mass Spectrometry Method for Quantification of Sonidegib in Capsule Dosage Form
}

\author{
Jayavarapu Kumar Raja ${ }^{1}$, Sundararajan Parimala Krishnan ${ }^{1 *}$, Vankayala Devendiran Sundar ${ }^{2}$ \\ ${ }^{1}$ Annamalai University, Annamalai Nagar-608002, Tamil Nadu, India \\ ${ }^{2}$ GIET School of Pharmacy, Chaitanya Knowledge City, Rajahmundry-533296, Andhra Pradesh, India
}

\author{
A R T I C L E I N F O \\ Article history: \\ Received: 27 June, 2020 \\ Revised: 19 August, 2020 \\ Accepted: 26 August, 2020 \\ Published: 30 September, 2020 \\ Keywords: \\ Accuracy, Basal cell carcinoma, \\ GC-MS, Linearity, Sonidegib, \\ Validation. \\ DOI: \\ 10.25004/IJPSDR.2020.120515
}

\begin{abstract}
A B S T R A C T
A new simple and precise gas chromatography-mass spectrometry (GC-MS) method was developed and validated for the quantification of sonidegib in the capsule formulation. The proposed work depends on the modification of sonidegib into its derivative with N, O-bis(trimethylsilyl)-trifluoracetamide (BSTFA) with $1 \%$ trimethylchlorosilane (TMCS). Selective ion monitoring technique and electron ionization method at $70 \mathrm{eV}$ were utilized for the quantification of sonidegib at $\mathrm{m} / \mathrm{z} 278$. The calibration plot was rectilinear in the concentration range of 0.5 to $10 \mu \mathrm{g} / \mathrm{mL}$. The relative standard deviation (RSD) value for withinday precision was $\leq 2.47 \%$ and for between-day precision was $\leq 2.45 \%$. The bias value for within-day and between-day accuracy was found between -1.51 to 1.87 . The intra- and inter-day recovery findings of sonidegib were found to be between 98.34 to $102.654 \%$ for pharmaceutical formulation. The limits of detection and quantification of sonidegib were 0.1 and $0.3 \mu \mathrm{g} / \mathrm{mL}$, respectively. No interfering peaks were observed from the excipients of dosage form during the analysis of formulation. The developed procedure was successfully applied to quantify commercial sonidegib capsule dosage form to estimate the sonidegib and check the dosage form uniformity of content.
\end{abstract}

\section{INTRODUCTION}

Sonidegib chemically designated as $N-[6-[(2 S, 6 R)$ -2,6-Dimethylmorpholin -4-yl]pyridin-3-yl]-2-methyl-3[4-(trifluoromethoxy) phenyl] benzamide with molecular formula of $\mathrm{C}_{26} \mathrm{H}_{26} \mathrm{~F}_{3} \mathrm{~N}_{3} \mathrm{O}_{3}$ and molecular weight of $485.498 \mathrm{~g} / \mathrm{mol}$ (Fig. 1). It is utilized to treat basal cell carcinoma, which has relapsed radiation therapy or after surgery in adult patients. It effectively obstructs the regulator called smoothened (SMO), inhibiting the hedgehog path from functioning. Consequently, cancers that depend on the hedgehog path were incapable of growing. ${ }^{[1-3]}$ The drug prevents a transmembrane protein called SMO, which plays an important role in the hedgehog (Hh)-signal transduction; this results in the prevention of Hh-signalling and anti-tumor activity in several animal models. ${ }^{[4,5]}$

The literature on the drug revealed that no GC-MS methods were reported for the quantification of sonidegib. ${ }^{[6,7]}$ The main aim of the present work was to develop and validate the GC-MS method with a simple and rapid sample preparation protocol to quantify sonidegib in pharmaceutical formulations.

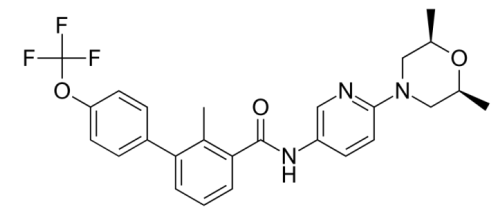

Fig. 1: Chemical structure of sonidegib

\footnotetext{
*Corresponding Author: Dr. Sundararajan Parimala Krishnan

Address: Associate Professor, Department of Pharmacy, Annamalai University, Annamalai Nagar-608002, Tamil Nadu, India

Email $\bowtie$ : drparimalakrishnan@gmail.com

Tel.: +91-9025211742

Relevant conflicts of interest/financial disclosures: The authors declare that the research was conducted in the absence of any commercial or financial relationships that could be construed as a potential conflict of interest.

Copyright (C) 2020 Jayavarapu Kumar Raja et al. This is an open access article distributed under the terms of the Creative Commons AttributionNonCommercial-ShareAlike 4.0 International License which allows others to remix, tweak, and build upon the work non-commercially, as long as the author is credited and the new creations are licensed under the identical terms.
} 


\section{MATERIALS AND METHODS}

\section{Chemicals and Reagents}

Sonidegib pure drug and Odomzo capsules (200 mg) were obtained from Sun Pharmaceuticals, Mumbai, India. N, O-bis(trimethylsilyl)-trifluoracetamide (BSTFA), trimethylchlorosilane (TMCS), and acetonitrile (99.8\% purity) were obtained from TCI Chemicals Pvt. Ltd., India.

\section{Instrument and Chromatographic Conditions}

Chromatographic elution was processed on an Agilent6890/N gas chromatographic system furnished with Series Mass-5973 detection system, autosampler 7673 series, and Chemstation software of Agilent Technologies, CA. HP-5MS stationary phase having a film thickness of $0.25 \mu \mathrm{m}$ and dimensions of $30 \mathrm{~m} \times 0.25 \mathrm{~mm}$ were utilized for the analysis. Helium gas at a flow rate of $1 \mathrm{~mL} / \mathrm{min}$ as a carrier gas and injection mode in the form of splitless was utilized. The detection system and injector temperatures were monitored at $245^{\circ} \mathrm{C}$. In the mass detector, parameters like transfer line temperature of $260^{\circ} \mathrm{C}$, solvent delay time of 3 minutes, and electron energy of $70 \mathrm{eV}$ were maintained.

\section{Preparation of Stock Solutions}

Sonidegib $1 \mathrm{mg} / \mathrm{mL}$ stock solution was executed in acetonitrile, and it was further diluted in acetonitrile to yield solutions of sonidegib $(10 \mu \mathrm{g} / \mathrm{mL})$. Calibration standards of sonidegib at concentrations of 0.5 to $10 \mu \mathrm{g} / \mathrm{mL}(0.5,1,2,4,6,8$, and $10 \mu \mathrm{g} / \mathrm{mL})$ were processed by spiking the correct quantity of the stock solution and kept at $+5^{\circ} \mathrm{C}$.

\section{Protocol for Quality Control Solutions}

Sonidegib quality control solutions of high, middle, and low levels were processed in acetonitrile to get $7.5,5$, and $1.25 \mu \mathrm{g} / \mathrm{mL}$, respectively, and were stored at $+5^{\circ} \mathrm{C}$. Further, these samples can be utilized for the assessment of different method validation parameters after thawing the quality control samples to room temperature.

\section{Protocol for Sample Preparation}

The mean of the 20 capsules was calculated from the weight of Odomzo capsules (200 mg sonidegib capsule, which has sonidegib and other excipients). These capsules were then subjected to grounding to get the fine powder. A calculated amount of fine powder was accurately weighed and transferred into a $100 \mathrm{~mL}$ volumetric flask and made up to the mark with acetonitrile. The resulting solution was vortexed for 10 minutes to dissolve the entire drug in the acetonitrile, and the solution was subjected to filtration through a no. 42 Whatman filter paper. Further, the resulting filtrate was subjected to serial dilution to get the sonidegib final solution within the working concentration range for GC-MS analysis.

\section{RESULTS}

\section{Method Optimization}

Sonidegib method development was executed for the estimation of the same, on the basis of chemical properties. Initially, the stationary phase and data acquisition conditions were elected to be a starting point for developing the method. Based on the solubility of sonidegib, the capillary stationary phase coated with 95\% dimethylpolysiloxane and 5\% phenyl is a choice for elution of sonidegib. The GC-MS conditions utilized in the development process depended on the boiling point and the injecting port and temperature of the detector set to $240^{\circ} \mathrm{C}$ for GC-MS. Variable temperature programming conditions were executed for the method. Finally, the GC-MS thermal programming was set as: starting temperature was $100^{\circ} \mathrm{C}$, processed for 1 -minute, raised to $200^{\circ} \mathrm{C}$, with $25^{\circ} \mathrm{C} /$ min increment, monitored for 1-minute, and at last set to $250^{\circ} \mathrm{C}$ with $10^{\circ} \mathrm{C} / \mathrm{min}$ increment, and processed for 1-minute. The temperature and time conditions were observed on reaction to fix the derivatization process of sonidegib. To $0.1 \mathrm{~mL}$ of sonidegib $(1,000 \mathrm{ng} / \mathrm{mL}), 0.1 \mathrm{~mL}$ of N,O-bis (trimethylsilyl)-trifluoracetamide (BSTFA) with $1 \%$ trimethylchlorosilane (TMCS) solution was mixed for the reaction at room condition, $50,60,70$, and $80^{\circ} \mathrm{C}$ for 15 , 30,45 , and 60 minutes. ${ }^{[8-11]}$ The resultant sample solutions were processed by the GC-MS system.

\section{Validation of Method}

Method validation was processed for the developed technique, as per the International Council for Harmonization (ICH) guidelines, and the parameters, viz., specificity, accuracy, linearity, the limit of detection (LOD), precision, the limit of quantification (LOQ), and stability were analyzed. ${ }^{[12]}$

\section{Specificity}

Method specificity was executed by investigating the intrusions between sonidegib and impurities, degradants, and excipients. Electron-impact ionization with SIM model was utilized for GC-MS quantification of sonidegib at $\mathrm{m} / \mathrm{z} 278$. The retention time of sonidegib for GC-MS was approximately 4.3 minutes, along with fine peak response in SIM and scan mode (Figs 2 and 3). ${ }^{[13]}$

\section{Linearity Plot}

Method linearity was executed by plotting the graph by taking the peak response of sonidegib on the Y-axis. The

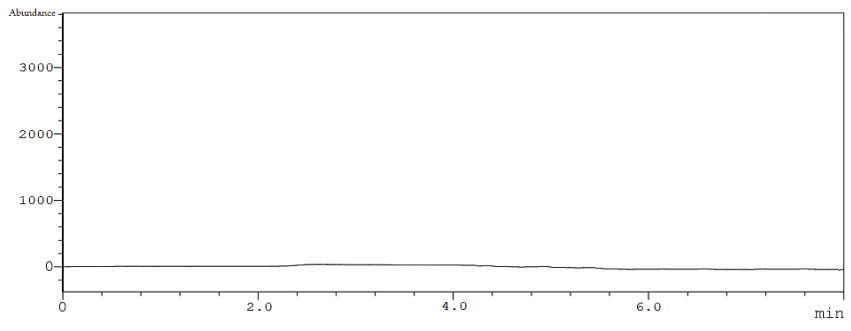

Fig. 2: Blank chromatogram of sonidegib 
Jayavarapu Kumar Raja et al.

Table 1: Linearity of sonidegib

\begin{tabular}{lllllll}
\hline Range $(\mu \mathrm{g} / \mathrm{mL})$ & $R E^{a}$ & $L O D(\mu \mathrm{g} / \mathrm{mL})$ & $L O Q(\mu \mathrm{g} / \mathrm{mL})$ & $R$ & $S a$ & $S b$ \\
\hline $0.5-10$ & $\mathrm{y}=419.04 \mathrm{x}+3.0162$ & 0.1 & 0.3 & 0.9998 & 1.5412 & 3.2168 \\
\hline
\end{tabular}

LOQ: Limit of quantification; RE: Regression equation; LOD: Limit of detection; y: Peak area; x: Sonidegib; ${ }^{\text {a: }}$ Six calibration curves; Sa:

Standard deviation of slope; Sb: Standard deviation of intercept

Table 2: Sonidegib accuracy and precision results

\begin{tabular}{|c|c|c|c|c|c|c|}
\hline \multirow{2}{*}{$\begin{array}{l}\text { Concentration } \\
(\mu \mathrm{g} / \mathrm{mL})\end{array}$} & \multicolumn{3}{|c|}{ Intra-day } & \multicolumn{3}{|c|}{ Inter-day } \\
\hline & Found $\pm S D$ & Accuracy & Precision $(\% R S D)^{a}$ & Found $\pm S D$ & Accuracy & Precision (\% RSD) \\
\hline 1.25 & $1.24 \pm 0.016$ & -0.89 & 1.86 & $1.26 \pm 0.021$ & 1.87 & 0.93 \\
\hline 5 & $5.04 \pm 0.072$ & 1.31 & 2.47 & $5.02 \pm 0.084$ & 1.54 & 2.45 \\
\hline 7.5 & $7.46 \pm 0.094$ & -1.46 & 2.08 & $7.45 \pm 0.076$ & -1.51 & 1.69 \\
\hline
\end{tabular}

${ }^{\mathrm{a}}$ Mean of six replicates; RSD: Relative standard deviation; SD: Standard deviation; Accuracy: \% relative error

Table 3: Sonidegib recovery results

\begin{tabular}{llllllll}
\hline & & \multicolumn{3}{c}{ Intra-day } & \multicolumn{3}{c}{ Inter-day } \\
\cline { 3 - 7 } Formulation & Spiked $(\mu \mathrm{g} / \mathrm{mL})$ & Found $\pm S D$ & \% recovery & \% RSD & Found $\pm S D$ & \% recovery & $\%$ RSD \\
\hline \multirow{2}{*}{ Odomzo $(0.5 \mu \mathrm{g} / \mathrm{mL})$} & 1.5 & $1.48 \pm 0.021$ & 99.31 & 2.43 & $1.49 \pm 0.036$ & 101.86 & 2.63 \\
& 4.5 & $4.47 \pm 0.062$ & 102.65 & 1.57 & $4.53 \pm 0.076$ & 98.68 & 1.49 \\
& 6.5 & $6.52 \pm 0.087$ & 98.46 & 1.93 & $6.47 \pm 0.094$ & 98.34 & 2.18 \\
\hline
\end{tabular}

${ }^{\mathrm{a}}$ Mean of six replicates; RSD: Relative standard deviation; SD: Standard deviation

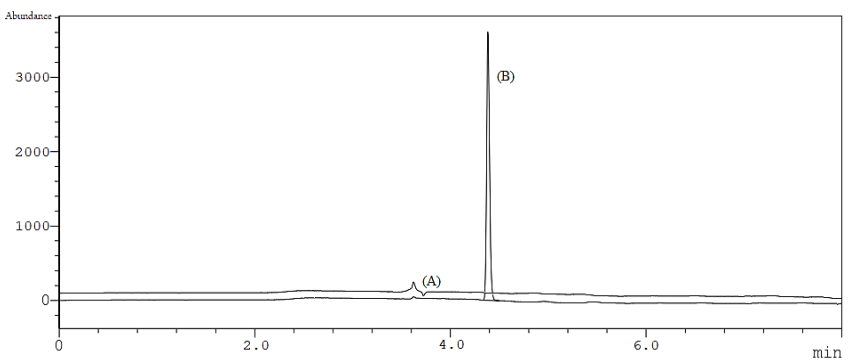

Fig. 3: Chromatograms of sonidegib (A) and derivatized sonidegib (B) (SIM mode)

$\mathrm{X}$-axis concentration was studied in a concentration range of 0.5 to $10 \mu \mathrm{g} / \mathrm{mL}^{\left[{ }^{[14-16]}\right.}$ The linearity plot was assessed for its regression equation and coefficient from six replicates and were found to be $y=419.04 x+3.0162$ and 0.9998 , respectively. These values prove that the developed method was linear over 0.5 to $10 \mu \mathrm{g} / \mathrm{mL}$. The findings are represented in Table 1 and Fig. 4.

\section{Precision and Accuracy}

In the present study, precision was evaluated in terms of within-day (repeatability) and between-day (intermediate) precision. ${ }^{[15]}$ Three concentrated differential solutions at $1.25,5$, and $7.5 \mu \mathrm{g} / \mathrm{mL}$ levels were assessed for six whiles in a day for repeatability and one time in a day for three days to estimate intermediate precision. The \% RSD value for repeatability and intermediate precision were found to be $\leq 2.47$ and $\leq 2.45 \%$, respectively. The percentage bias for within- and between-day accuracy was found between -1.51 to 1.87 , and the values are tabulated in Table 2.

\section{Recovery}

To evaluate the accuracy of the present work and to find out the interfering components of formulation excipients,

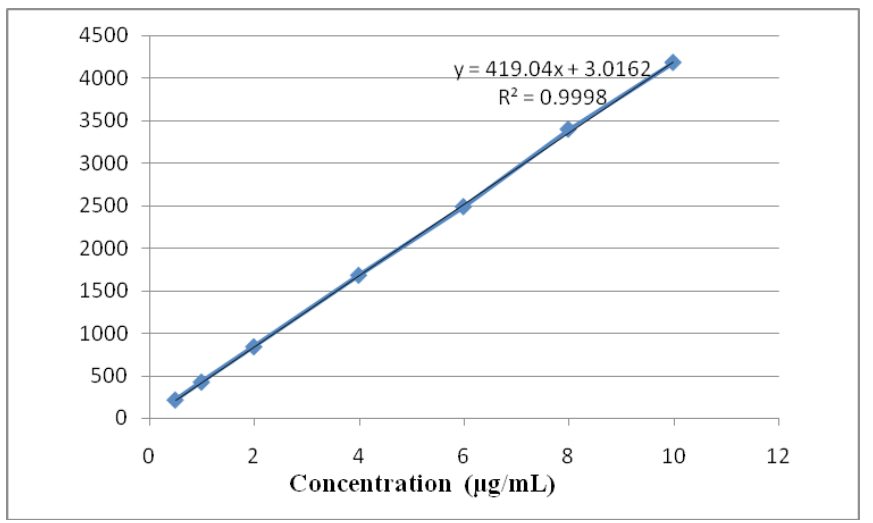

Fig. 4: Calibration curve of sonidegib

the amount recovered was tested as three variable concentrations $(1.5,4.5$, and $6.0 \mu \mathrm{g} / \mathrm{mL})$, and recovery of analyte was executed by the addition of a known quantity of pure analyte to pre-analyzed sample solutions of marketed formulations. ${ }^{[13,16]}$ The percentage of recovery findings were calculated by equating obtained concentration from the spiked solutions with original concentrations. The resulting findings are shown in Table 3.

\section{Limit of Detection (LOD) and \\ Limit of Quantification (LOQ)}

The LOD and LOQ were executed with different kinds of sonidegib stock dilute solutions to achieve a signalto-noise ratio of 10:1 for LOQ and 3:1 for LOD. The LOQ and LOD findings for sonidegib were 0.3 and $0.1 \mu \mathrm{g} / \mathrm{mL}$, respectively, and represented in Table 1.

\section{Stability Study}

These studies were executed to prove the stability nature of the analyte and at which temperature and time it was 
Method Development and Validation of Sonidegib in Capsule Dosage Form by GC-Mass Spectrometry

Table 4: Sonidegib stability data in solution

\begin{tabular}{lcccccc}
\hline \% stability & \multicolumn{3}{c}{ Refrigeratory stability $+4^{\circ} \mathrm{C}$} & \multicolumn{2}{c}{ Room temperature stability } & \multicolumn{2}{c}{ Frozen stability $-20^{\circ} \mathrm{C}$} \\
\cline { 2 - 7 } Added $(\mu \mathrm{g} / \mathrm{mL})$ & \multicolumn{2}{c}{$\% A \pm R S D$} & \multicolumn{2}{c}{$\% A \pm R S D$} & $\% A \pm R S D$ \\
\hline 1.25 & $100.61 \pm 1.25$ & $101.41 \pm 1.26$ & $101.22 \pm 1.27$ & $100.83 \pm 1.08$ & $101.68 \pm 1.75$ & $101.56 \pm 1.42$ \\
5 & $101.29 \pm 1.79$ & $102.29 \pm 1.46$ & $101.31 \pm 1.81$ & $101.46 \pm 1.34$ & $100.97 \pm 1.76$ & $102.24 \pm 1.49$ \\
7.5 & $100.57 \pm 1.27$ & $101.9 \pm 1.35$ & $100.83 \pm 1.29$ & $100.94 \pm 1.81$ & $100.64 \pm 1.56$ & $102.5 \pm 1.38$ \\
\hline
\end{tabular}

A: Recovery; RSD: Relative standard deviation

Table 5: Analyses results of sonidegib by different analysts

\begin{tabular}{lllllll}
\hline & \multicolumn{3}{c}{ Intra-day } & \multicolumn{3}{c}{ Inter-day } \\
\cline { 2 - 7 } Spiked $(\mu \mathrm{g} / \mathrm{mL})$ & Found $\pm S D$ & \% recovery & \% RSD & Found $\pm S D$ & \% recovery & \% RSD \\
\hline 1.5 & $1.49 \pm 0.031$ & 98.65 & 1.84 & $1.47 \pm 0.029$ & 99.54 & 1.56 \\
4.5 & $4.48 \pm 0.071$ & 101.8 & 1.46 & $4.52 \pm 0.08$ & 98.85 & 1.08 \\
6.5 & $6.53 \pm 0.076$ & 99.21 & 2.57 & $6.49 \pm 0.084$ & 101.6 & 2.18 \\
\hline
\end{tabular}

${ }^{\mathrm{a}}$ Mean of six replicates; SD: Standard deviation

undergoing decomposition by monitoring the samples at $+4^{\circ} \mathrm{C}$, room temperature, and refrigerated $\left(-20^{\circ} \mathrm{C}\right)$ for the time of 24 hours as short-term stability and refrigeration temperature at +4 and $-20^{\circ} \mathrm{C}$ for the time of 72 hours as long-term stability. The resultant findings of short-term and long-term stability studies are shown in Table 4.

\section{Method Ruggedness}

To perform the ruggedness analysis, sonidegib quantification was processed on GC-MS by the different analysts on the same equipment with the same procedure. The results (Table 5) disclosed that there was no significant variation in the results obtained by the different analysts and the method proved the ruggedness parameter.

\section{DISCUSSION}

In present days, the HPLC and GC-MS techniques play a key role in identifying and quantitating different kinds of drug components. They are essential for the pharmaceutical industries to resolve the impurities, degradants, and metabolites. The sensitivity of the GC-MS technique is very low to quantify the sonidegib concentrations in different solutions. Hence, to overcome this problem, $\mathrm{N}, \mathrm{O}$-bis(trimethylsilyl)-trifluoracetamide with $1 \%$ trimethylchlorosilane was elected as a chromogenic reagent for the derivatization of the analyte.

A literature survey on sonidegib discloses that no GC-MS technique was developed for the quantification of sonidegib in different kinds of dosage forms. The current research work produces the validated analytical method for the separation and quantification of sonidegib by GC-MS method. The GC-MS method validation objective is to get the precise, accurate, and constant findings during the identification and quantification of pharmaceutical dosage forms and APIs.

The proposed work depends on the derivatization of sonidegib into its derivative with BSTFA with 1\% TMCS.
Selective ion monitoring technique and electron ionization method at $70 \mathrm{eV}$ were utilized for the quantification of sonidegib at $\mathrm{m} / \mathrm{z} 278$. HP-5MS stationary phase having a film thickness of $0.25 \mu \mathrm{m}$ and dimensions of $30 \mathrm{~m} \times 0.25 \mathrm{~mm}$ were utilized for the analysis. Helium gas at a flow rate of $1 \mathrm{~mL} / \mathrm{min}$ as a carrier gas and injection mode in the form of splitless was utilized. The detection system and injector temperatures were monitored at $245^{\circ} \mathrm{C}$. In the mass detector, parameters like transfer line temperature of $260^{\circ} \mathrm{C}$ and solvent delay time of 3 minutes were maintained.

The developed method was subjected to validation and processed for accuracy, LOD, precision, LOQ, specificity, ruggedness, and linearity parameters. The calibration plot was processed and proved by a rectilinear graph in the concentration range of 0.5 to $10 \mu \mathrm{g} / \mathrm{mL}$ (Table 1). The coefficient of correlation value of 0.9998 represents the linearity of the method. The precision studies were executed in terms of within- and between-day precision (Table 2). The \% RSD values for within- and between-day precisions were $\leq 2.47$ and $\leq 2.45 \%$, respectively, proved that the developed method was precise. The bias value for within- and between-day accuracy was found between -1.51 and 1.87 . The intraand inter-day recovery findings of sonidegib were found to be between 98.34 to $102.654 \%$ for pharmaceutical formulation (Table 3).

The LOD and LOQ findings of sonidegib were 0.1 and $0.3 \mu \mathrm{g} / \mathrm{mL}$, respectively. These values represent the sensitivity of the method by derivatization. The stability of the sample solution was very important for every analyst during the method of analysis. The analyst must know the sample's degradation time in a particular solvent system at different temperature conditions. So, the stability studies were processed at $+4^{\circ} \mathrm{C}$, room temperature, and refrigerated $\left(-20^{\circ} \mathrm{C}\right)$ temperatures as short- and long-term stability. The findings of the stability (Table 4) proved 
that the drug has optimum stability for the analysis. The method was also subjected to the ruggedness study by the different analysts on the same instrument. The findings (Table 5) of the study shown that the developed method was rugged.

\section{CONCLUSION}

The research work depended on the derivatization of sonidegib into its derivative with $\mathrm{N}, \mathrm{O}$-BSTFA with $1 \%$ TMCS. Selective ion monitoring technique and electron ionization method at $70 \mathrm{eV}$ were utilized for the quantification of sonidegib at $\mathrm{m} / \mathrm{z} 278$. HP-5MS stationary phase having a film thickness of $0.25 \mu \mathrm{m}$ and dimensions of $30 \mathrm{~m} \times 0.25 \mathrm{~mm}$ were utilized for the analysis. Helium gas at a flow rate of $1 \mathrm{~mL} / \mathrm{min}$ as a carrier gas and injection mode in the form of splitless was utilized. The detection system and injector temperatures were monitored at $245^{\circ} \mathrm{C}$. In the mass detector, parameters like transfer line temperature of $260^{\circ} \mathrm{C}$ and solvent delay time of 3 minutes were maintained. The calibration plot was rectilinear in the concentration range of 0.5 to $10 \mu \mathrm{g} / \mathrm{mL}$. The RSD value for within-day precision was $\leq 2.47 \%$ and for between-day precision was $\leq 2.45 \%$. The intra- and inter-day recovery findings of sonidegib were found to be between 98.34 to $102.654 \%$ for pharmaceutical formulation. The LOD and LOQ findings of sonidegib were 0.1 and $0.3 \mu \mathrm{g} / \mathrm{mL}$, respectively. The developed procedure was successfully applied to quantify commercial sonidegib capsule dosage form to estimate the sonidegib and check the dosage form uniformity of content.

\section{REFERENCES}

1. Pan S, Wu X, Jiang J, et al. Discovery of NVP-LDE225, a Potent and Selective Smoothened Antagonist. ACS Medicinal Chemistry Letters. 2010;1:130-134.

2. Einolf HJ, Zhou J, Won C, Wang L, Rebello S. A physiologicallybased pharmacokinetic modeling approach to predict drug-drug interactions of sonidegib (LDE225) with perpetrators of CYP3A in cancer patients. Drug metabolism and disposition. $2017 \mathrm{Apr}$ 1;45(4):361-374.
3. Fendrich V, Wiese D, Waldmann J, Lauth M, Heverhagen AE, Rehm J, et al. Hedgehog inhibition with the orally bioavailable Smo antagonist LDE225 represses tumor growth and prolongs survival in a transgenic mouse model of islet cell neoplasms. Annals of Surgery. 2011;254:818-823.

4. Burness CB. Sonidegib: First Global Approval. Drugs. 2015;75:15591566.

5. Ashley E Ross, Robert M Hughes, et al. Pharmacodynamic and pharmacokinetic neoadjuvant study of hedgehog pathway inhibitor Sonidegib (LDE-225) in men with high-risk localized prostate cancer undergoing prostatectomy. Oncotarget. 2017;8:104182-104192.

6. Zollinger M, Lozac'h F, Hurh E, Emotte C, Bauly H, Swart P. Absorption, distribution, metabolism, and excretion (ADME) of C-14-sonidegib (LDE225) in healthy volunteers. Cancer ChemotherPharmacol.. 2014;74:63-75.

7. Saili XIE, Xiaoxia HU, Lei YE. Study on the Pharmacokinetics of Sonidegib in Rats. Lat. Am. J. Pharm.. 2018;37:1933-7.

8. Greenway W, Whatley FR. Resolution of complex mixtures of phenolics in poplar bud exudate by analysis of gas chromatographymass spectrometry data. J. Chromatogr. A. 1990;519:145-158.

9. Soleas, G J. Ultrasensitive assay for three polyphenols (catechin, quercetin and resveratrol) and their conjugates in biological fluids utilizing gas chromatography with mass selective detection. J. Chromatogr. B Biomed. Sci. Appl. 2001;757: 161-172.

10. Gehrke CW, Leimer K:Trimethylsilylation of amino acids, derivatization and chromatography. J. Chromatogr.. 1971;57: 219.

11. Knapp D R. Handbook of Analytical Derivatization Reactions; 1979. John Wiley and Sons: New York 9.

12. International Conference on Harmonisation (ICH) of technical requirements for registration of pharmaceuticals for human use:harmonised tripartite guideline on validation of analytical procedures: methodology, Recommended for Adoption at Step 4 of the ICH Process on November. 1996 by the ICH Steering Committee, Published by IFPMA, Switzerland.

13. Yilmaz B, Arslan S, Akba V. Gas chromatography-mass spectrometry method for determination of metoprolol in the patients with hypertension. Talanta. 2009;80:346-351.

14. Zhang Y, Zhang G, Zhang Y. Occurrence and analytical methods of acrylamide in heat-treated foods: Review and recent developments. Journal ofChromatography A. 2005;1075:1-21.

15. Mastovska K, Lehotay S J. Rapid sample preparation method for LC-MS/MSor GC-MS analysis of acrylamide in various food matrices. Journal of Agricultural and Food Chemistry. 2006;54:70017008.

16. Lagalante AF, Felter MA. Silylation of acrylamide for analysis by solid phase microextraction/gas chromatography/ion-trap mass spectrometry. Journal of Agricultural and Food Chemistry. 2004;52:3744-3748.

HOW TO CITE THIS ARTICLE: Raja JK, Krishnan SP, Sundar VD. Method development and validation of gas chromatography-mass spectrometry method for quantification of sonidegib in capsule dosage form. Int. J. Pharm. Sci. Drug Res. 2020;12(5):532-536. DOI: 10.25004/IJPSDR.2020.120515 